I Like Cities; Do You Like Letters? Introducing Urban Typography in Art Education

\title{
Ricard Huerta
}

\begin{abstract}
This article proposes a study of the letters and graphics found in the city, while at the same time opening up unusual spaces linked to the cultural arena and visual geographies for the creation of learning spaces in art education, introducing urban typography for training teachers. The letters in urban spaces can help us reinterpret the patrimonial fabric of cities. With the help of typography, visual arts educators have a powerful graphic resource with which to articulate the complex communicative network of streets. We suggest walking as an aesthetic practice; strolling around the city as a very cultural means to motivate our students. We have at our disposal in our cities a genuine museum woven together with the threads of the alphabet.
\end{abstract}


Why do we offer street letters as a persuasive and educational element?

This is an invitation to a typographic stroll, and a bridge towards a persuasive wealth of visual contact. From an early age we are taught how to read, to write, to interpret texts. But the efficacy of letters goes beyond their mere verbal meaning, and we should be attentive to the repercussions these legible forms (street signs) end up having on the landscape of the city - very especially on account of their creative and political potential (Freedman 2008). The city presents itself to us full of messages, of elements that can turn out to be very attractive if we observe them from new, interdisciplinary, suggestive or creative standpoints. In this article we are not proposing to go deeply into pedagogical detail but open up a new rich seam which we hope will be mined by other teachers interested in the field. Following letter trails we find trajectories that lead us to heritage, to literature, to photography and to the educational context.

Calligraphy and typography has powerful communicative effects in arts, as Antoni Tàpies, Joaquín Torres-García, Robert Indiana, Edward Ruscha, Cy Twombly, Jenny Holzer and other artists have shown. Important art movements such as Cubism or Conceptual Art have used letters as a creative support. We have the responsibility (as professionals in art education) to contemplate values, references, parameters and information about multiple visual artefacts. Letters and writing symbols offer us new opportunities in order to creative exigencies in art education. Admittedly, we have to consider the necessities of our pupils when developing learning strategies. Certain cultural aspects belonging to everyday practices, such as typography or calligraphy (even the design of letters), should be better valued by visual arts educators - something which is not currently taking place. If we considered the forms and the cultural load of letters in art classes, both from the theoretical viewpoint and in image creation workshops, we will be encouraging a new link between the tradition of the arts, certain aspects of urbanism, computer graphics and especially ICT. In this way we will be able to approach certain of the pupils' interests, taking advantage of historical and patrimonial aspects as well as the more pressing issues related to technology such as computer design or the manipulation and creation of characters. This would also help us to improve the appreciation and observation criteria of some visual products coming from the arts, design, urbanism or the media.

Big city streets are filled with graphic documents in which letters and symbols occupy a central place, not only as verbal texts, but also as a privileged graphical and visual register. Also posters, signs and graffiti constitute a powerful typographical ensemble peculiar to the environment of the city. When designers manage their ideas and creations they really place their work, which is usually born from commercial approaches, within our reach. Usually, this is a mass-production model (think, for example, of the $\mathrm{M}$ in $\mathrm{McDonalds);}$ these are the objects with which producers and creators defend their positions in the form of a dialogue with the target client. In offering these products in the public space of the street, these visual devices bear a flow committed to users, that is, to us citizens who people the streets (also when we go by car, bus, underground or bicycle). As Careri (2002) argues in his work, posters, signs and graffiti constitute a powerful typographical ensemble peculiar to the environment of the city. One of the most fruitful settings in the urban encounter with letters is the advertising poster. Whether they are permanent or temporary posters (papers stuck onto a fence or a wall), they are usually advertising products and activities, and therefore generate an information model that enriches changes in the urban landscape. Even in Cuba, a country in which commercial advertisements are not distributed, we can still see them in the streets, albeit with a political and social slant.

The encounter with urban signboards produces an experience that we can compare to certain perceptions activated in the user when visiting a museum. Our contention starts from the premise that the museum is not solely a container of pieces - protected, mythologised, institutionalised and geographically located (this is shown and transgressed by a growing interest 


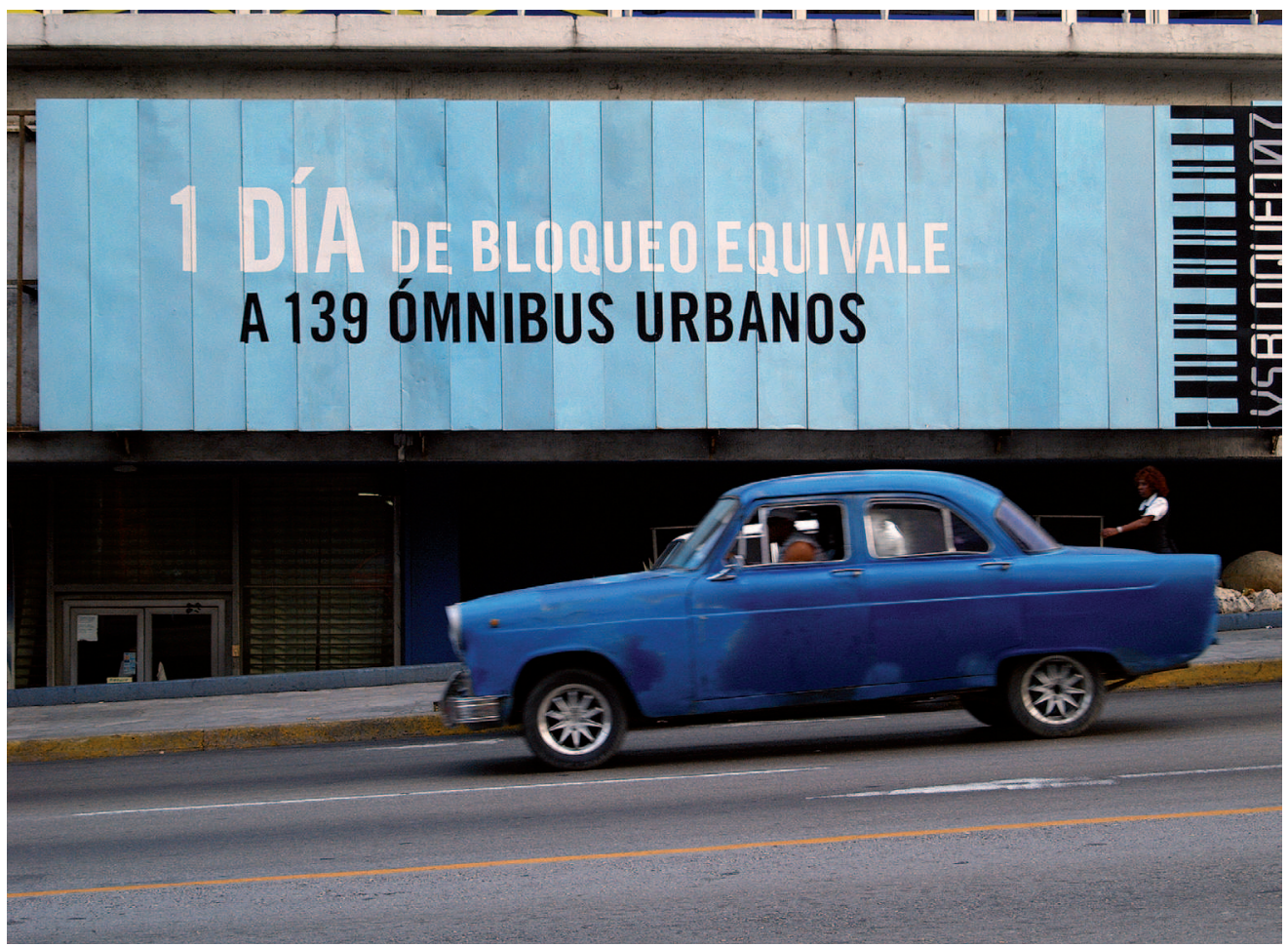

in museums' virtual versions displayed on the web). We propose that it is rather the attitude of the visitor which causes a significant experience, both in the museum and outside it (Chang 2006; Fontal 2007). If we transfer this idea of reflective enjoyment to the citizen who roams the city (their own, or any other they may visit), then we lift the barriers which keep the museum isolated from certain sociological realities, and turn a public environment, such as the streets of the city, into one which serves the learning needs of every person. Starting methodologically with the analysis carried out by Colette Dufresne-Tassé (1995, 2478 ) of studies on museum visitors, we understand that our proposal would be located in section 6 of the categories defined by the Canadian author: studies in which the visitor is considered in terms of the enjoyment and the satisfaction that the experience provides them.

In addition to conceiving of the city as a space apt for enjoyment and learning, we propose that the walker generates their own cataloguing when walking the city (Francesco Careri establishes a clear connection between walking and the history of art), not only in the places where the city shows its traditional charms (monuments, historic sites, commercial areas), but mainly in the so-called non-places, spaces located on the border, dowdy places, metaphors of social abandonment (Careri 2002).

We want to encourage the city walker to generate their own visual speech from images, from photographs taken by pupils interested in their own urban environments (this creative argument was defended three decades ago by Donis Dondis). In contrast to the traditional imposition of the museum space, where it is usually forbidden to take photos, the urban environment is revealed as an open landscape, without aesthetic restrictions. Digital devices easily allow us to turn whatever we perceive into images. While we capture a living moment or a discovered territory, we also decide the way of doing it, the composition we wish for it, and certainly what we overlook or emphasize.

Prohibitions are part of popular iconography. Expressions like 'no fly-posting' or 'no entry', are used repeatedly on the walls. As designers we 


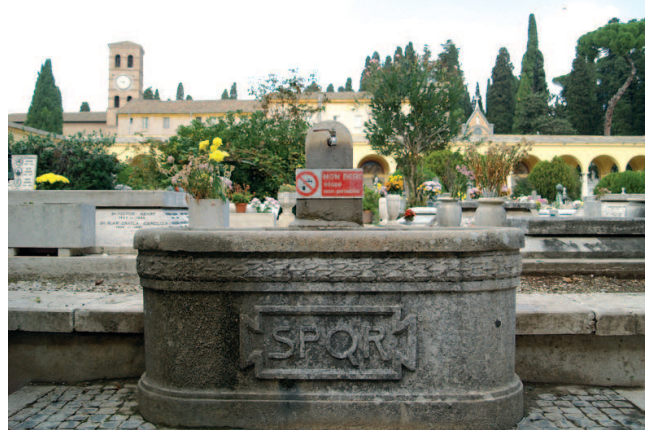

would pay attention to the ways of laying out the graphic composition of such posters. But from other areas we can deal with different issues to do with these posters: like citizens' rights, public and private spaces, the charm they generate, or the information that they convey. We are exposed to textual interests, because typography is present at every step that we take, every space that we use displays texts on the walls, the objects that we manipulate contain texts, and we are all guided by texts on computer, mobile phone or television screens (Huerta 1994; 2005). Anyone trying to develop some type of written work will have to make decisions about the aspect and the composition of letter design, even when questions appear at the level of mere information, since the use of the computer keyboard acquaints us constantly with the use of typographical characters.

In spite of a certain overuse of typography on computer screens, it is surprising that we know so little about the alphabet as a cultural form. It is unusual, in most cases, to know exactly to what extent the shapes of letters have influenced our history, especially in the last five centuries, with the progressive development of printing and engraving techniques, all the way to the computer as the logical outcome of the process. Professionals in art education can take a new approach to typography as an educational discourse, since the borderline nature of the typographic letter (halfway between graphic language and verbal written language) allows us to address a number of processes from the standpoint of transversality. We believe that the present moment encour- ages the recognition of typography as a determining factor in our communication processes, without rejecting the ideological potential of the aesthetic aspect surrounding our involvement (Duncum 2008).

\section{Beginning with teacher training}

As we see it from our early-twenty-first century standpoint, considering the changes that are taking place in the university context, it would be convenient to approach the letter as a visual element in the same way that we access contemporary art (Lachapelle 2007). The study of typography might offer transversal material, very much in line with the teaching of visual arts in primary and secondary education (even at university), with a special emphasis on the education of teaching staff (future official masters of teachers' training). We believe that the key moment lies precisely in teacher training. Let us recall that in all official primary school teachers' curricula in Spain before 1970 (precisely when teacher training studies entered the university) writing skills were decisively valued (even with its own subject called 'Calligraphy'). Neglect increased after reform plans in 1997, when the subject 'New Technologies Applied to Education' was introduced. An excellent opportunity was lost due to the fact that these subjects were located in areas of knowledge to be taught by specialists in general didactics and/or mathematicians, without anybody noticing something which stood out: the fact that the screen is a graphical space. In fact, it is often thought that an aspect of knowledge is not adequately addressed in the curriculum if it does not have its allotted hours per week in the school schedule, or if it does not at least have one specific subject that covers it. In this situation we need new ideas in art education.

From the perspective of art education we manage the different images, uses and strategies which qualify us to transmit the graphic value of written texts. In fact, even at present, one of the main functions of teachers consists in teaching children how to read and write. If a few decades ago an art teacher could help future teachers to develop certain skills with the materials of writing (in the name of consistency with reality), a person
75

Ricard Huerta

Opposite page:

Figure 1

The 'Versus Bloqueo

$07^{\prime}$ campaign filled the city of Havana with messages related to the international economic blockade against Cuba. Posters were designed with a firmly typographical approach, since they displayed only capital letters on a monochrome background.

This page:

Figure 2

Cemeteries constitute a splendid typographic showcase. Photography is forbidden in the Verano cemetery in Rome, something unusual in most cemeteries. 


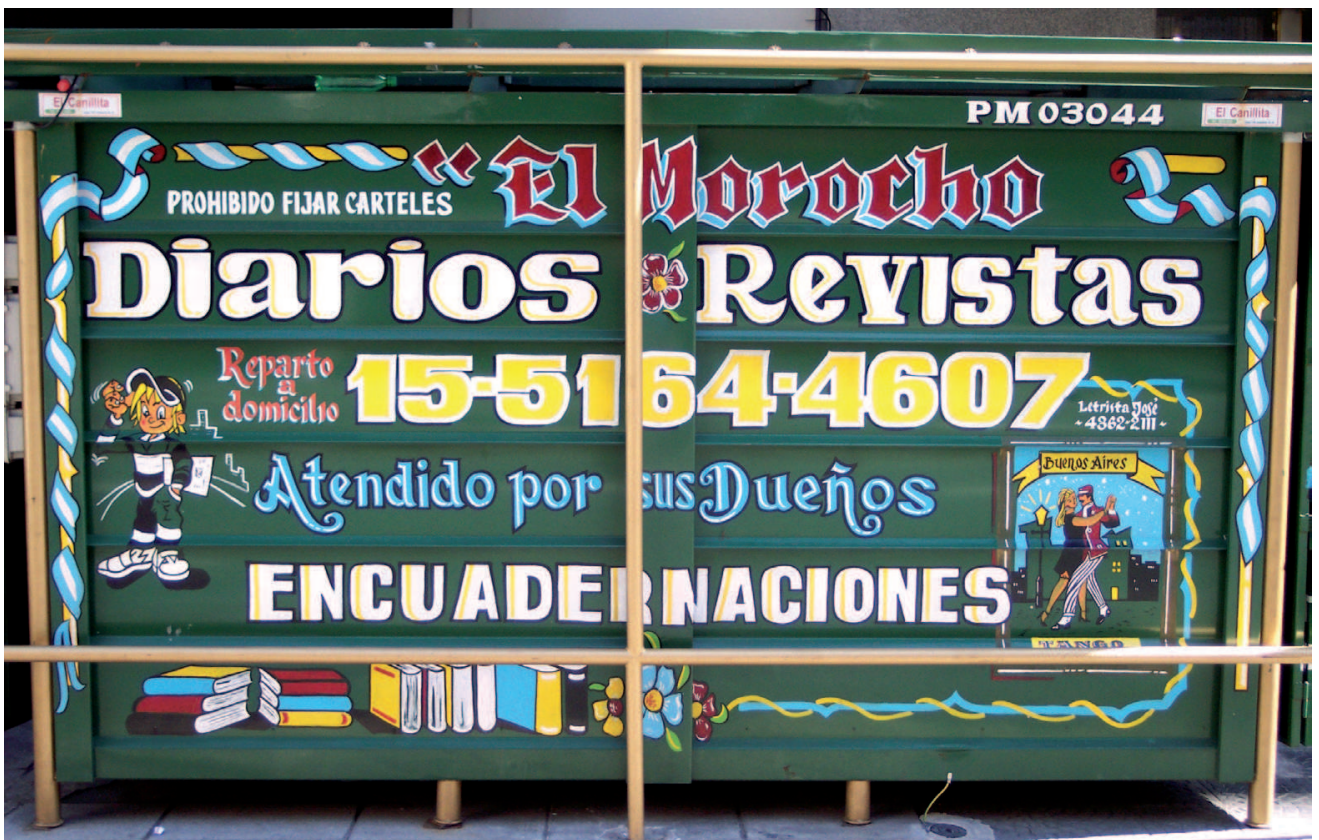

who is going to dedicate themselves to education would need to know a series of essential aspects related to typography, and by extension, to graphic design. Taking into account the significant presence of typography in the uses of ICT, it would bevery rewarding for teachers to know the history, the functioning and the compositional rules of this graphic aspect of texts.

It is difficult to connect with students at nursery, primary or secondary levels of schooling unless proper teacher training has taken place. It is convenient to introduce visual culture issues in the humanistic training of teachers. Marzilli (2008) points up certain complexes haunting educators, who neither consider themselves specialists in art nor artists, and who are afraid of not being able to approach their art classes appropriately. The author suggests that their own colleagues, specialist teachers and museum educators, should encourage teachers in educational uses of artistic learning. Classroom proposals can also increase confidence and draw students to art. Although most education professionals like to read and expand their cultural capital in multiple ways, on very few occasions are they allowed explore the architectural and visual aspects of letters and the alphabet. This is especially serious if we consider that the alphabet and numbers are their raw materials of communication.

Educators are not provided with sufficient information about the visual contribution and cultural tradition of letters, calligraphies and typographies - what they do know was probably acquired by chance or out of sheer curiosity. Yet this is not enough, since a relevant element in visual training is ultimately left to personal discretion. Institutions should assume the challenge of better teacher training in a field which iscentral to their activity: the alphabet, the letters. Beyond the verbal meanings of words, letters hide a graphic and symbolic code that connects directly with our cultural heritage (Huerta 2008). It is not enough to decipher contents: the layout of texts acquires an additional value when it can relate to other disciplines.

\section{The $\mathrm{ABC}$ of the question}

We know something about letters, but we know little about them. What kind of rationale governs the alphabet? What countries have the letter ' $\tilde{n}$ ' on their keyboards? Why was it decided that letter shapes were to be displayed on the top lefthand corner of computer keys? What happens with keyboards in countries such as Russia, 
China, Israel, India or Saudi Arabia, where other alphabets are used? All these questions betray a lack of knowledge about the code that helps us communicate, a visual instrument that cities display at every corner. Art educators vindicate creative spirit to solve problems, a type of intuition analysed by Paul Duncum, and recently by John Steers (2009). In order for this type of knowledge to reach the classroom, we must try and engage future teachers in this task. We suggest one possibility through studying letters as graphic and cultural signs in the urban context.

It is advisable to endow educators with indispensable notions for their work, such as a knowledge of the history, social and cultural development, technical factors and also the ideological patterns that have marked the signs of writing, so we can better understand current uses of information technologies. The place where this renewed interest in typography should start is the university classroom, where future teachers receive their training, as well as professional development courses for practising teachers. We have obtained very good results when expert training in this area has been given to teachers. We found out that they feel more at ease researching about letters, as a graphic area which do not cause them discomfort. These teachers were originally trained with handwritten texts, whereas children nowadays use computer keyboards or mobile phones even before developing writing skills with a pen or pencil on paper. In this sense, calligraphy is rapidly giving way to computer-typographical characters. Future teachers (who are currently switching from analogue to digital systems) should be prepared to tackle these issues from a very permeable position in close connection with other work-related and sociological issues (Mirzoeff 2003). Kathy Marzilli has studied the degree of apprehension and dissatisfaction felt by many of these teachers in art teaching. As they are not professionals specializing in art education, the need to teach art subjects causes a profound unease in them. The author shows in her study that this anxiety stems from the teachers' alleged lack of competence in art-related matters. We are aware of the validity of arguments such as those outlined by Marzilly (2008). In our teacher-training classes, we have seen that the introduction of calligraphy and typography as sources of study and appropriation makes art more accessible.

When asking prospective teachers about their relationship to art, Marzilli elicited the following answer: 'I am not an artist, I can't draw.' We handle this initial answer by asking another question: 'Can you write?' The answer of the students is rewarding and resounding: 'Yes, of course we can write.' From there, we ask them to do some exercises in which drawing and writing go together. In this way, initial fears and apprehensions are overcome. This process needs a more generous approach in dealing with cultural aspects as essential as the graphic design of letters or signs. This has implications for the further understanding of the graphic design of letters, which affects the drawing ability of both students and teachers. Given the fact that there is disagreement between the interests of students and what is conveyed by their teachers (different generations, analogue and digital systems), we may use typography as a permeable material, as a graphic vehicle for multiple contents capable of bridging the gap between pupils and teachers, in the art education scene. Letters invite a reflection on the city, evaluating local aspects versus global perspectives, as suggested by Freedman (2008) in her review of critical aspects such as creativity or identities in art education.

\section{Evaluation results through pictures}

For this study, we focus on the surveys conducted on a group of university students on the optional course 'Introduction to photography'. They were 40 students, from many different disciplines, although the highest percentage (55\%) was drawn from education students, as this course was taught at a University of Valencia teacher training centre in 2008. The students did not know basic aspects of graphic composition or elementary issues about the language of images (except for two students who were studying audiovisual communication). They were given four tasks, to develop over a four-month period (the time available for this course between March and June). The first sessions of the workshop were somewhat complex, as the students neither knew each

77

Ricard Huerta 


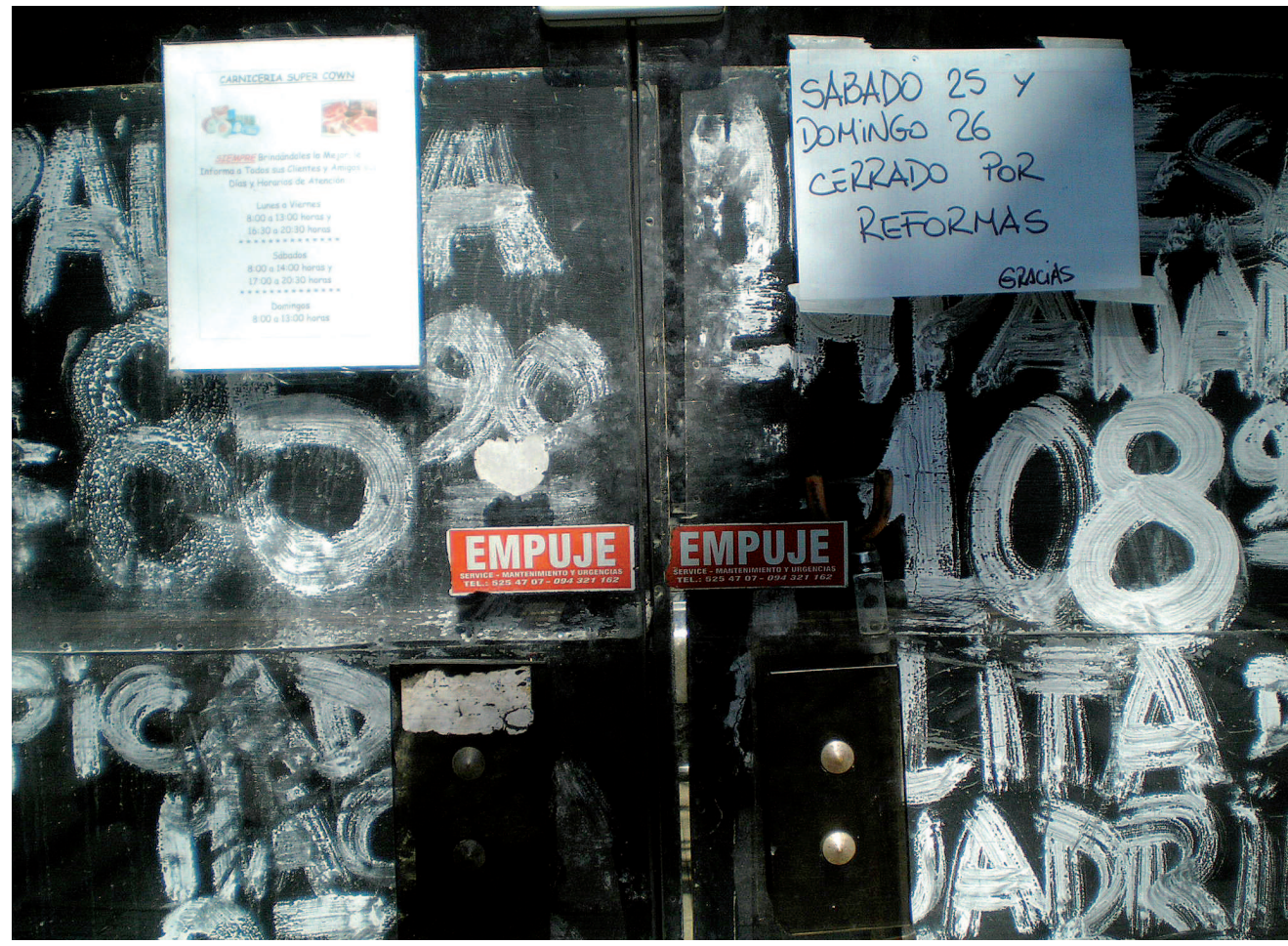

other, nor were familiar with photography or other aspects of the visual arts. These shortcomings were evident in the initial anonymous survey carried out on the first day. Through this questionnaire, it was found out that never before (at any of the education levels they had gone through) had they discussed photography or photographers, let alone typography. They were unaware of the fact that a director of photography has a determining role in a film or that press photography requires specialist professionals. After a month of workshop activity, these students presented the results of their first piece. The project entitled 'Landscape: letters from the city' involved choosing a city tour and taking pictures in which letters have their own compositional space. Twelve of these images were selected and were then shown to the whole group.

To observe and describe the city (drawing, photographing, recording video, painting) involves the acceptance of graphic messages that cover their architecture. The processes of urban change are constant, sometimes traumatic, and can be analysed both by using theory and by creating our own images. Thus the student develops a new reading of the city by looking more closely at their surroundings. When we come to know more about our surroundings, we manage to establish a critical relationship with them. Discovering the city, preferably on foot, means tracing its history, its weaknesses, its peculiarities, its innovations. The idea of becoming a tourist in your own city is rather shocking for students. Can you be a tourist in the place where you live? In fact, this reflection reveals a broader paradox: usually we do not know our immediate environment. We found that our students had come to 'rediscover' their own city when engaged in this task. It is about using the identity references. This approach to the city is a way of reclaiming heritage (Agra 2007; Csikzentmihalyi 1990; Fontal 2007; Huerta 2008). With these proposals we generate processes around cultural heritage from an emotional dimension, without losing sight of sociological and cultural aspects (Lynch 1998; Romano 2008).

We collected 40 anonymous surveys focused on the exercise 'Landscape: letters from the city' (32 women, 8 men). All of those asked shared a 


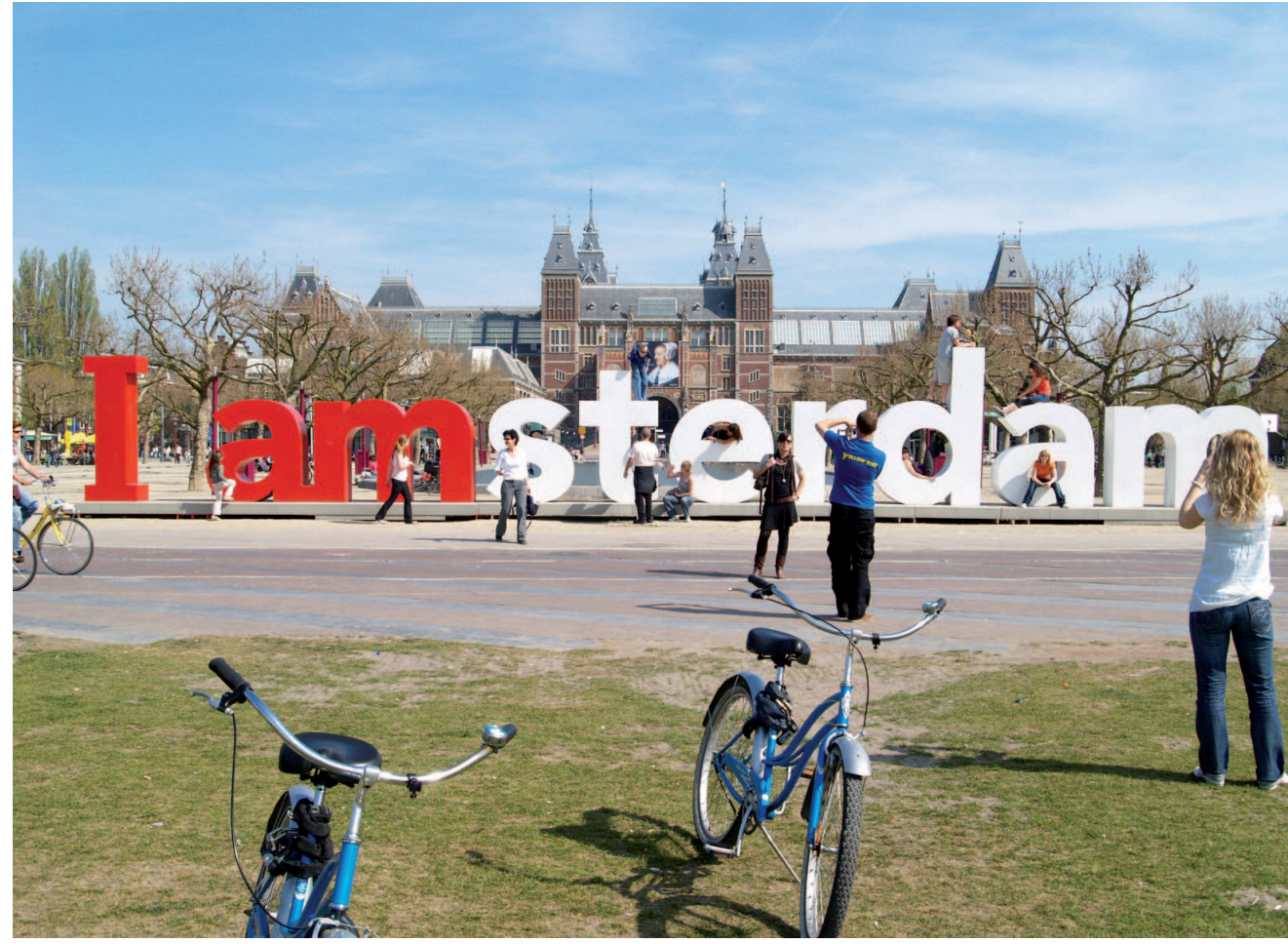

positive or very positive opinion of the project. They had never before worked with this methodology (except in four cases). A student acknowledges: 'it seems to me a good method because it makes you grasp the work rationale rather than just do it'. Or: 'before, when taking pictures, I only focused on what I wanted to convey, without attaching importance to ideological and cultural aspects'. Some $65 \%$ of those asked pointed out that 'it helped me to learn more about my own city"'.

When asked about the creative and communicative ability of the proposal, a student answered: 'I think that now I am a bit more of an artist when I take photos... I try to capture things than before I didn't even perceive'. And also in a sociological sense: 'I have photographed my neighbourhood. My intention was to show its beauty but also its poverty: el Carmen is an area full of historical richness, but very messy. It is striking to see the number of beautiful drawings on the walls, the whole world can see them, but they are not an exhibit in a museum.' A student acknowledges the discovery: 'Never before had I photographed my own neighbourhood', while another student said: 'I've had the opportunity to discover an artistic gift that I didn't know I possessed.' Another reconstructs his intentions: 'In photographing my own city, but not my neighbourhood, I intended to convey the everyday.

The anonymous questionnaire, as a tool of analysis and evaluation of the proposal, has helped us redefine many aspects: the students' relationships with the class group, their personal connections with the portrayed city, and of course their contact with art and artistic production. Practical experiences are recorded in the class book, in which each student registers their impressions, as in a portfolio: 'In this exercise I had the intention of enjoying myself, that is to say: I was literally lost in a neighbourhood that I already knew.' When the experience is gratifying, feelings of satisfaction emerge-'I have enjoyed the creative freedom that was granted by the exercise', - without losing sight of the technical and expressive achievements: "it has given me a greater understanding of the camera and the techniques of photography'. Another writes: 'I have developed an interest and now I'm taking pictures of other cities". It is impor-
79

Ricard Huerta

Opposite page:

Figure 4

Calligraphy has powerful communicative effects, as artists like Antoni Tàpies and $\mathrm{Cy}$ Twombly have shown. The strength of the calligraphic gesture is present in this metal door photographed in Montevideo.

This page:

Figure 5

In the theoretical sessions prior to the workshop, students received basic information about scenery, photography, art and typography. The sculpture located on the Museumplein in Amsterdam was the subject of an advertising campaign for tourism, aimed at countering doubts and prejudices. 
tant that the university students can count on this kind of curricular proposals (Huerta 2004; Wexler 2007), especially those who do not study for Art and Graphic Design.

\section{Conclusions}

Experience of the city, especially one's own city, considered from the angle of its typographic wealth, is related to enjoyment and learning. In a similar way to what we experienced in the museum visits by creating significant actions (Chang 2006; Hooper-Greenhill 1994), our attitude as visitors to the city can be articulated in relation to the texts which cover the urban fabric. In order to get citizens to think critically about their environment, we suggest walking as an aesthetic practice, and the creation of pictures as a personal artistic intervention. In this sense, calligraphy and typography should be considered an important graphic resource in art education exercises, and used by teachers to educate. For this interest to reach new generations, we consider the training of educators to be a critical rung on this ladder. In this way, writing understood as drawing and representation, facilitates the practice of artistic activities - a standpoint from which it is much easier to bring art to college students. The positive results offered by photography as a reflection on the city (following the plot threads of urban letters), allows us to rethink our social, cultural and educational roles. As Hernández (2007) indicated over defining pedagogical guidelines is contra-productive to a subject dependent on the freedom and intuition of the intervention, we have preferred to leave this part open. However in general, we have been able to verify the value of this approach, based on a qualitative study with a group of university students. The positive results offered by photography as a reflection on the city (following the threads of urban letters), allows us to rethink our social, cultural and educational roles. Becoming tourists in our own city implies reinventing the concept of tourist, of city, and of citizenship.

\section{Acknowledgement}

I am grateful to Jara Díaz, Andrew Duncun, Andreu Balius and Luis Hernán Errázuriz for their comments and advice on various drafts of this article.

\section{References}

Agra, M. J. (2007) Geografías personales: un lugar donde detenerse, in R. Calaf, O. Fontal \& R. E. Valle [Eds] Museos de arte y educación. Construir patrimonios desde la diversidad. Gijón: Trea, pp. 305-18

Careri, F. (2002) Walkscapes. El andar como práctica estética. Barcelona: Gustavo Gili

Chang, E. (2006) Interactive experiences and contextual learning in museums, Studies in Art Education, Vol. 47, No. 2, pp. 170-86

Csikzentmihalyi, M. (1990) The Art of Seeing: An Interpretation of the Aesthetic Encounter. Los Angeles: The J. Paul Getty Trust

Dufresne-Tassé, C. (1995) Andragogy (adult education) in the museum: a critical analysis and new formulation, in E. Hooper-Greenhill [Ed.] Museums, Media, Message. New York: Routledge, pp. 245-9

Duncum, P. (2008) Holding aesthetics and ideology in tension, Studies in Art Education. Vol. 49, No. 2, pp. 122-35

Fontal, O. (2007) ¿Se están generando nuevas identidades? Del museo contenedor al museo patrimonial, in R. Calaf, O. Fontal \& R. E. Valle [Eds] Museos de arte y educación. Construir patrimonios desde la diversidad. Gijón: Trea, pp. 27-52

Freedman, K. (2008) Leading creativity: responding to policy in art education, in $\mathrm{R}$. Mason \& T. Eça [Eds] International Dialogues about Visual Culture, Education and Art. Bristol: Intellect, pp. 39-47

Hooper-Greenhill, E. (1994) Museums and Their Visitors. London: Routledge 
Huerta, R. (1994) Funció plàstica de les /letres.

Huerta, R. (2004) Sangre o tinta. La tipografía como argumento liminar para una educación artística, Ponencias Primer Congreso de Tipografía. Valencia: ADCV, pp. 178-86

Huerta, R. (2005) Apaga-la! València: Institució Alfons el Magnànim

Huerta, R. (2008) Museo Tipográfico Urbano. Paseando entre las letras de la ciudad.

Valencia: PUV

Lachapelle, R. (2007) Aesthetic dispositions and hypotheses formulation as evaluations of non-expert viewers' responses to public contemporary art, in E. Nardi [Ed.]Thinking, Evaluating, Re-thinking. Milan: Franco Angelli, pp. 273-80

Lynch, K. (1998) La imagen de la ciudad. Barcelona: Gustavo Gili

Marzilli, K. (2008) Attitudes of preservice general education teachers toward art, Visual Arts Research, Vol. 34, No. 1, pp. 53-62

Mirzoeff, N. (2003) Una introducción a la Cultura Visual. Barcelona: Octaedro

Romano, M. (2008) La città come opera d'arte. Turin: Giulio Einaudi Editore

Steers, J. (2009) Creativity: delusions, realities, opportunities and challenges, International Journal of Art and Design Education, Vol. 28, No. 2, pp. 126-38

Wexler, A. (2007) Museum culture and the inequities of display and representation, Visual Arts Research, Vol. 33, No. 1, pp. 25-33 